\title{
COMUNICAÇÃOCIENTÍFICA
}

\section{OCORRENCIA DE AFÍDEOS CAUSANDO DANOS EM MANGUEIRA (Mangifera indica L.), NO VALE DO SÃO FRANCISCO' ${ }^{1}$}

\author{
RACHEL GONÇALVES FERREIRA² e FLÁVIA RABELO BARBOSA ${ }^{3}$
}

\begin{abstract}
RESUMO - Observaram-se em pomares de mangueiras (Mangifera indica L.), no semi-árido nordestino, altas infestações de afídeos causando danos às folhas novas e brotações da planta. Diversas amostras foram coletadas, tendo sido identificadas três espécies: Aphis craccivora, Aphis gossypii e Toxoptera aurantii. As duas primeiras espécies estão sendo relatadas pela primeira vez como pragas, em mangueiras, no Brasil. Espécimens de referência encontram-se depositados no Laboratório de Entomologia da Embrapa Semi-Árido, localizada em Petrolina-PE.
\end{abstract}

Termos para indexação: Aphididae, Aphis craccivora, Aphis gossypii, Toxoptera aurantii, pragas.

\section{OCCURRENCE OF APHIDS DAMAGING MANGO (Mangifera indica L.), IN THE SÃO FRANCISCO VALLEY}

\begin{abstract}
A high infestation of aphids was observed at private orchards of mango (Mangifera indica L.) in the Brazilian northeast, with significant damage to young leaves, buds and inflorescences of the plants. Three aphid species were identified from collected samples: Aphis craccivora, Aphis gossypii and Toxoptera aurantii. In Brazil, this is the first record of $A$. craccivora and $A$. gossypii as pest on this fruit crop. Voucher specimens are deposited at the Entomology Laboratory of the Embrapa Semi-árido Research Center.
\end{abstract}

Index terms: Aphididae, Aphis craccivora, Aphis gossypii, Toxoptera aurantii, aphid pests.

O semi-árido nordestino é privilegiado pela suas condições climáticas, possibilitando a colheita da manga exatamente na entressafra de outras regiões, favorecendo a comercialização tanto no mercado interno quanto no externo. A escassez pluviométrica e a baixa umidade relativa do ar induzem à produção de frutos com melhor coloração, alto teor de açúcar e isentos de doenças típicas de outras regiões. Contudo, a alteração do agroecossistema, provocada pela expansão de plantio dessa anacardiácea, tem propiciado o aumento de insetospraga.

A ocorrência de afídeos em mangueira, em condições de campo, não é comum no Brasil. Entretanto, na safra 1999/ 2000, observaram-se altas infestações de afídeos causando danos às plantas, em prospecções realizadas em três áreas empresariais: Mapel, Fruitfort e Timbaúba e em três áreas de pequenos produtores, pertencentes ao Projeto de Irrigação Senador Nilo Coelho. O objetivo deste trabalho foi identificar as espécies de afídeos associadas aos danos nas referidas áreas. Em cada área, foram escolhidas, ao acaso, quatro plantas para a realização das amostragens de brotações e inflorescências. Estas amostragens foram realizadas a cada 10 dias, por um período de 1 ano (fevereiro/2000 a janeiro 2001), coletando-se, ao acaso, duas brotações e uma inflorescência nos quatro quadrantes da planta. Os afídeos foram encontrados na face inferior das folhas (Figura 1), em brotações ou em inflorescências. Nas folhas, os danos iniciais observados foram um amarelecimento acompanhado de mela, substância açucarada liberada pelos afideos que, posteriormente, favoreceu o crescimento do fungo que causa a fumagina, dando um aspecto escuro às folhas. Os danos observados nas inflorescências foram murcha e queda das flores, causando redução na produção de frutos. Esses danos foram os mais encontrados no campo.

Amostras de folhas e inflorescências, colonizadas por afídeos, foram coletadas nas áreas estudadas. Os afídeos foram transferidos para álcool comercial (95\%), onde permaneceram até o processo de clarificação e montagem, o qual foi feito, seguindo-se a metodologia descrita por Ilharco \& Gomes (1966) e Ilharco \& Lemos (1981). A identificação foi feita, observandose as características morfológicas dos insetos, conforme as seguintes chaves: Cottier (1953), Eastop (1966), Holman (1974) e Martin(1983).

As espécies identificadas foram: Aphis craccivora Koch, Aphis gossypii Glover e Toxoptera aurantii (Boyer de Fonscolombe) (Hemiptera: Aphididae). A. gossypii foi encontrado apenas em uma das amostras coletadas, nas inflorescências, em coabitação com as outras espécies. Verificou-se que agosto foi o mês em que houve o mais alto índice de infestação (49,75\%), encontrado na fazenda Timbaúba, embora tenha sido observado, nas diferentes áreas, que os afídeos ocorreram em todos os meses do ano. A. craccivora foi a espécie mais encontrada nas

1 (Trabalho 087/2001). Recebido: 13/04/2001. Aceito para publicação: 08/02/2002.

2 Enga. Agra. Dr ${ }^{\mathrm{a}}$., Empresa Pernambucana de Pesquisa Agropecuária (IPA); caixa postal 1022, CEP 50761-000 - Recife - PE. E-mail: rachel@cpatsa.embrapa.br

$3 \mathrm{Eng}^{\mathrm{a}}$. Agr ${ }^{\mathrm{a}}$. Dra., Embrapa Semi-Árido; caixa postal 23, CEP 56300-000 - Petrolina - PE. E-mail: flavia@cpatsa.embrapa.br 


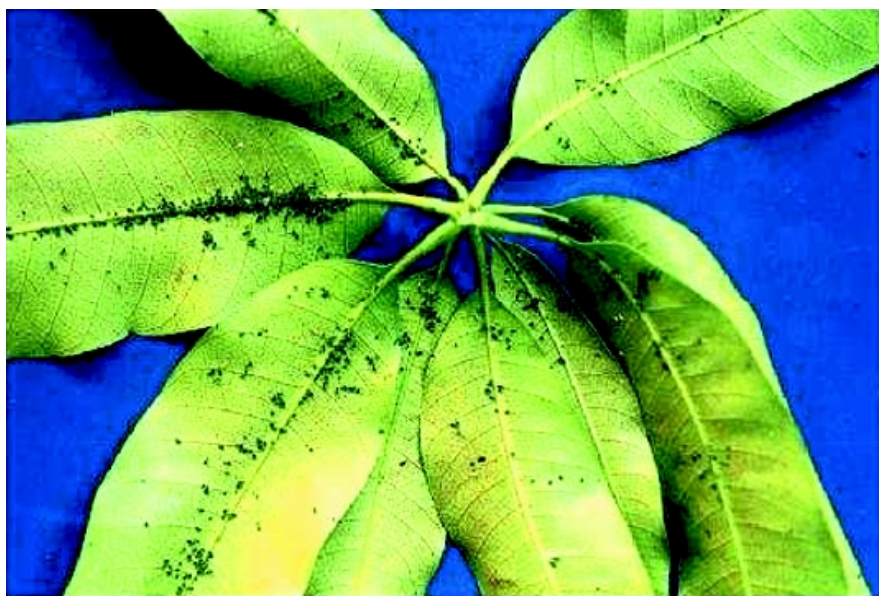

FIGURA 1 - Colônias de afídeos em folhas de mangueira.

amostragens.

Tanto A. craccivora como T. aurantii são de coloração preta. Quando observados com o auxílio de um microscópio estereoscópio, os ápteros da primeira espécie apresentam áreas dorsais esclerosadas, negro brilhante, enquanto os alados apresentam dorso abdominal com franjas ou placas esclerosadas que nunca se fundem em um escudo dorsal como nos ápteros. A segunda espécie, T. aurantii, apresenta os segmentos antenais III-V pálidos com ápices escuros, e a nervura média das asas anteriores apresenta uma só bifurcação, e o pterostigma, quase negro. A. gossypii são afídeos muito pequenos, bem menores que as outras duas espécies citadas e têm, numa mesma população, coloração variada desde amarelo-clara a verde-escura ou são negros. Estas espécies foram citadas anteriormente como pragas da mangueira, em outros países, por Blackman \& Eastop $(1984,1994)$ e Peña \& Mohyuddin (1997). No Brasil, Santos et al. (1981) citaram o afídeo T. aurantii causando danos em mudas dessa cultura, na região dos cerrados, ou seja, no Distrito Federal. Este é o primeiro relato de $A$. craccivora e $A$. gossypii como pragas da referida cultura, no País.

Os espécimens de referência encontram-se depositados no Laboratório de Entomologia da Embrapa Semi-Árido.

\section{REFERÊNCIAS BIBLIOGRÁFICAS}

BLACKMAN, R.L.; EASTOP, V.F. Aphids on the world's crops. New York: J. Wiley, 1984. 466p.

BLACKMAN, R.L.; EASTOP, V.F. Aphids on the world's trees: an identification and information guide.: Wallingford: $\mathrm{CAB}$ International/Natural History Museum, 1994. 987p.

COTTIER, W. Aphids of New Zealand. Wellington: Department of Scientific and Industrial Research, 1953.382p. (Bulletin, 106).

EASTOP, V.F. A taxonomic study of australian Aphidoidea (Homoptera). Australian Journal of Zoology, Melbourne, v.14, p.399-592, 1966.

HOLMAN, J. Los áfidos de Cuba. La Habana: Instituto Cubano del Libro, 1974. 304p.

ILHARCO, F.A.; GOMES, A. Montagem de afídeos para observação microscópica. Introdução de uma nova operação. Agronomia Lusitana, Oeiras, v.28, n.1, p.41-45, 1966.

ILHARCO, F.A.; LEMOS, A. Algumas notas sobre a montagem de afídeos para observação microscópica (Homoptera, Aphidoidea). Agronomia Lusitana, Oeiras, v.41, n.1, p.53-57, 1981.

MARTIN, J.H. The identification of common aphid pest of tropical agriculture. Tropical Pest Management, Basingstok, v. 29, n.4, p. 395-411, 1983.

PEÑA, J.E.; MOHYUDDIN, A.I. Insect pest. In: LITZ, R.E. (Ed.) The mango: botany, production and uses. Wallingford: $\mathrm{CAB}$ International, 1997. Cap. 10, p.327-362.

SANTOS, G. P. PINTO, A.C. Q. Biologia de Cycloneda sanguínea e sua associação com afídeo em mudas de mangueira. PesquisaAgropecuária Brasileira, Brasília, v.16, n.4, p. 473-476, 1981. 